\title{
COMPATIBILIDADE ENTRE TRATAMENTO DE SEMENTES DE AMENDOIM COM FUNGICIDAS, SOBREVIVÊNCIA DE RHIZOBIUM E NODULAÇÃO ( $\left.{ }^{(}\right)$
}

\author{
ELI SIDNEY LOPES $(2,4)$ e EDILBERTO PRINCI PORTUGAL $\left(^{3}\right)$
}

\section{RESUMO}

Conduziu-se um experimento para testar a compatibilidade dos fungicidas captã, PCNB e tirã com a inoculação de sementes de amendoim, cujo tratamento se efetuou simultaneamente com a inoculação ou dez dias antes desta. No momento da inoculação e quatro horas após, fez-se uma contagem de Rhizobium nas sementes, pelo método da diluição e inoculação de gotas em placas, mantendo-se um controle sem aplicação de fungicida. Para se estudar o e feito dos tratamentos na nodulação e fixação, plantaram-se as sementes em solo esterilizado, avaliando-se a nodulação e o teor de ureídeos nas folhas. Somente o captã aplicado simultaneamente à inoculação foi prejudicial à sobrevivência bacteriana nas sementes. De maneira geral, a aplicação dos fungicidas simultaneamente à inoculação mostrou-se prejudicial em relação à antecipada.

Termos de indexaçậ: Rhizobium-fưngicida, compatibilidade; amendoim, Arachis hypogaea L.

(1) Apresentado na XIII Reuniāo Latino-Americana sobre Rhizobium, em 19-25 de outubro de 1986, Panamb. Recebido para publicação em 21 de novembro de 1985.

(2) Seção de Microbiologia do Solo, Instituto Agronômico (IAC), Caixa Postal 28, 13001 Campinas (SP).

( $\left.{ }^{3}\right)$ Biólogo, estagiário, Seçāo de Microbiologia do Solo (IAC).

(4) Com bolsa de suplementaçäo do CNPq. 


\section{INTRODUÇÃO}

O tratamento de sementes de amendoim com fungicidas é prática usual no Estado de São Paulo e recomendada por órgãos responsáveis pela produção e comercialização de sementes certificadas. LAGO et alii (1976) comprovaram os efeitos benéficos dos fungicidas tirã, captã e PCNB na preservação das sementes de amendoim. Entretanto, segundo alguns autores, a desinfecçāo propiciada por fungicidas poderia, em contrapartida, prejudicar a infecção ou interferir nos processos de fixação do nitrogênio atmosférico, conforme observado em outras leguminosas (CURLEY \& BURTON, 1975; GRAHAM et alii, 1980).

Neste trabalho, procurou-se avaliar os efeitos de tratamentos envolvendo os fungicidas captā, PCNB e tirã na sobrevivência de Rhizobium em sementes de amendoim, no peso e número de nódulos, e na fixação de nitrogênio atmosférico, com base na concentração de ureídeos presentes nas folhas da planta de amendoim.

\section{MATERIAL E MÉTODOS}

Conduziram-se dois experimentos, sendo um em laboratório, para determinar a influência dos fungicidas na sobrevivência da bactéria, e outro em casa de vegetação, com piantas crescidas em vaso para estudar a influência na nodulação e desenvolvimento. No primeiro ensaio, trataram-se as sementes de amendoim (Arachis hypogaea L.), cv. Tatu, previamente esterilizadas com radiação gama (2,5 Mrad), com os fungicidas tirã [(dissulfeto de tetrametiltiuram, $70 \%$ ) + + lindane $(\gamma-1.2 .3 .4 .5 .6$ - hexacloronitrobenzeno, $1 \%)]$, captã ( $\mathrm{N}$-triclorometilmercapto-4-cicloexano-1.2.-dicarboximida, $50 \%+$ lindane $1 \%$ e PCNB (pentacioronitrobenzeno, $75 \%$ ).

Utilizaram-se os seguintes tratamentos, constando cada qual de três repetiçōes:

1. Inoculação, sem fungicida (controle);

2. Tratamento com tirã e inoculação simultânea;

3. Tratamento com captā e inoculação simultânea;

4. Tratamento com PCNB e inoculação simultânea;

5. Inoculação dez dias após tratamento com tirã;

6. Inoculação dez dias após tratamento com captã;

7. Inoculação dez dias após tratamento com PCNB.

Nos tratamentos com fungicidas, as sementes foram homogeneizadas com os produtos até perfeita cobertura, em quantidades equivalentes às doses de $1,0 \mathrm{~g}$ de tirã, ou $3,5 \mathrm{~g}$ de captã ou 2,0g de PCNB por quilograma de sementes. Para a inoculação, aplicou-se, por $100 \mathrm{~g}$ de sementes, $0,4 \mathrm{~g}$ de inoculante turfoso preparado com turfa irradiada e com a estirpe SMS-400Re, mutante resistente a 200 ppm de estreptomicina, já constatada como eficiente em amendoim (GIARDINI et alii, 1980), apresentando $9 \times 10^{9}$ bactérias/grama de turfa. Imediatamente após a inoculação, efetuou-se a contagem do número de rizóbios nas sementes 
do tratamento controle e, quatro horas depois, a de todos os tratamentos. Para a contagem de bactérias sobreviventes, utilizou-se o método das gotas descrito por VINCENT (1970), em meio de manitol-levedura, com 200 ppm de estreptomicina e duas gotas de Micostatin/250 $\mathrm{ml}$ de meio.

No experimento em vasos, na casa de vegetação, efetuaram-se os mesmos tratamentos, com cinco repetições em solo esterilizado com 2,5 Mrad de radiação gama ou não esterilizado, mantendo-se os vasos inteiramente casualizados. O solo - um Latossolo Vermelho-Amarelo álico, A moderado, textura argilosa, sob vegetação de cerrado - era proveniente do Centro Experimental de Campinas. A análise química mostrou os seguintes resultados: aluminio: 0,95 ; cálcio: 0,75 ; magnésio: 0,40 (em e.mg/100ml de T.F.S.A.); potássio: 66,0 ; fósforo: 1,75; manganês: 9,75 ; zinco: 0,42 ; cobre: 1,75 e ferro: 54,0 (ppm) $\left({ }^{5}\right) ; 2,9 \%$ de matéria orgânica, e pH 5,1 (RAlJ \& QUAGGIO, 1983). A adubação consistiu nas dosagens (mg/kg de solo) de $\mathrm{CaCO}_{3} 1027 ; \mathrm{MgCO}_{3} 220$; superfosfato triplo $672 ; \mathrm{K}_{2} \mathrm{SO}_{4} 65$; enxofre elementar 20; $\mathrm{ZnSO}_{4} \cdot 7 \mathrm{H}_{2} \mathrm{O} 7 ; \mathrm{MnSO}_{4} \cdot \mathrm{H}_{2} \mathrm{O}$ 8; $\mathrm{CuSO}_{4} \cdot 5 \mathrm{H}_{2} \mathrm{O} 2 ; \mathrm{Na}_{2} \mathrm{~B}_{4} \mathrm{O}_{7} \cdot 10 \mathrm{H}_{2} \mathrm{O} 2 ;\left(\mathrm{NH}_{4}\right)_{6} \mathrm{Mo}_{7} \mathrm{O}_{24} \cdot 4 \mathrm{H}_{2} \mathrm{O} 0,01 ; \mathrm{FeSO}_{4} .7 \mathrm{H}_{2} \mathrm{O} 3$.

Coletou-se, peneirou-se e colocou-se o solo para secar duas semanas antes de empregá-lo, acondicionando-o então em sacos plásticos $(1,5 \mathrm{~kg} / \mathrm{saco})$ e adicionando-se carbonato de cálcio e de magnésio (em solução). Após homogeneização, mantiveram-se os sacos em casa de vegetação durante 25 dias. Em seguida, aplicou-se superfosfato triplo (na forma de pó) e os nutrientes restantes (solução) ao solo, homogeneizando-o e conservando-o em casa de vegetaçăo por 28 dias e transferindo-o para vasos de alumínio $(17,0 \mathrm{~cm}$ de diâmetro da boca $\times 10,5 \mathrm{~cm}$ de base $\times 13,5 \mathrm{~cm}$ de altura) desinfetados e com capacidade para $1,5 \mathrm{~kg}$ de solo.

As sementes do ensaio foram obtidas de vagens previamente selecionadas e desinfetadas com sublimado corrosivo (1:1000) por 1,5 minuto e lavadas quatro vezes com água esterilizada. As sementes foram recolhidas assepticamente, descartando-se as úmidas. Quatro horas depois da inoculação, efetuou-se o plantio e, após a germinạaão, o desbaste, deixando-se duas plantas por vaso.

Para a determinação do teor de ureídeos, coletaram-se folhas novas, totalmente expandidas, decorridos 49 e 73 dias do plantio. Realizou-se a análise de ureídeos pelo método de YOUNG \& CONWAY (1942), modificada por STREETER (1979).

\section{RESULTADOS E DISCUSSÃO}

\section{Efeito dos fungicidas na sobrevivência de Rhizobium nas sementes}

Com base nos resultados das contagens de rizóbios nas sementes não tratadas com fungicidas, verificou-se uma queda de $66,0 \%$ na sobrevivência

(5) Análise feita pela Seçāo de Pedologia - IAC. 
bacteriana, quatro horas após a inoculação. SALEMA et alii (1979) observaram um decréscimo de cerca de $90 \%$ dos rizóbios viáveis em apenas uma hora, associando-a à dessecação ocorrida nas sementes. Alguns produtos, como a mistura sacarose-glutamato, podem minimizar esse efeito quando aplicados durante a inoculação.

A sobrevivência bacteriana na semente foi significativamente prejudicada quando se aplicou o captã simultaneamente à inoculação. O PCNB, na mesma forma de aplicação, parece ter estimulado o desenvolvimento das bactérias nas sementes. Ambos os produtos empregados com dez dias de antecedência, e o tirã, nas duas formas de aplicação, não afetaram a sobrevivência de Rhizobium (Figura 1). De maneira geral, a aplicação dos fungicidas simultaneamente à inoculação mostrou-se prejudicial à sobrevivência bacteriana em relação à antecipada, visto que as médias do número de bactérias nesses grupos de tratamentos apresentaram diferenças estatisticamente significativas.

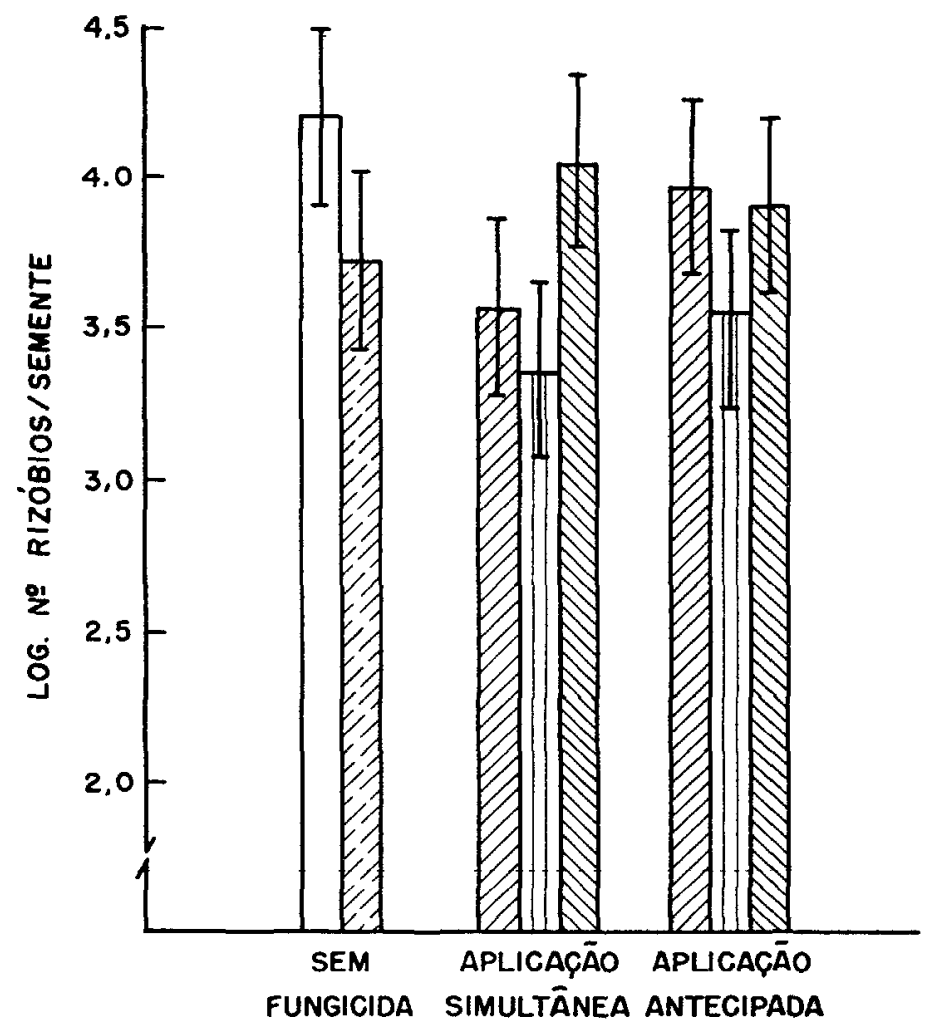

FIGURA 1. Número de rizóbios/semente observado no momento da inoculação de sementes não tratadas com fungicida $\square$ e quatro horas após a inoculação, em sementes não tratadas CTZ ou tratadas com tirã $\oslash$, captã IID e PCNB $\square$, aplicados simultaneamente ou dez dias antes da inoculação. 
GRAHAM et alii (1980) obtiveram resultados semelhantes, utilizando os mesmos produtos em contato com Rhizobium phaseoli: constataram que, apesar do efeito tóxico do PCNB, sobreviveram 48 horas após o contato com o produto acima de $10^{3}$ rizóbios/grama de semente. STAPHORST \& STRIJDOM (1976), investigando os efeitos de treze fungicidas, in vitro, em estirpes de Rhizobium capazes de nodular Vigna unguiculata, verificaram que cinco produtos, entre eles o PCNB, foram os menos tóxicos. No entanto, CURLEY \& BURTON (1975) observaram que o PCNB foi incompativel com Rhizobium japonicum.

GRAHAM et alii (1980) verificaram que o captã foi mais tóxico que o PCNB e o tirā, causando rápida queda de viabilidade bacteriana. Outros autores constataram a influência tóxica do captã, ora moderada, ora bactericida, dependendo da estirpe de Rhizobium e da concentração do produto (AFIFI et alii, 1969; GILLBERG, 1971; KECSKÉS \& VINCENT, 1969; DIATLOFF, 1970; MAKAWI \& ABDEL-GHAFFAR, 1970; FISHER, 1976; STAPHORST \& STRIJDOM, 1976). CURLEY \& BURTON (1975) observaram que o captã não afetou a sobrevivência de $R$. japonicum.

Tem-se observado, em alguns casos, compatibilidade do tratamento com tirā e inoculação de sementes (CURLEY \& BURTON, 1975; RUSCHEL \& COSTA, 1966), embora efeitos moderados e até marcadamente tóxicos tenham sido relatados (GRAHAM et alii, 1980; AFIFI et alii, 1969; KECSKÉS \& VINCENT, 1969; DIATLOFF, 1970; KECSKÉS, 1970; STAPHORST \& STRIJDOM, 1976).

Podem-se atribuir as diferenças nos resultados da literatura, a diferenças na tolerância das estirpes empregadas (BRACKEL, 1963). Para uma mesma estirpe de Rhizobium, é possivel selecionar mutantes resistentes a certos defensivos (ODEYEMI \& ALEXANDER, 1977).

\section{Nodulação}

Os efeitos dos fungicidas na nodulação, analisados em duas épocas, podem ser visualizados no quadro 1, para solo irradiado. Não se constataram efejtos deletérios dos produtos, tanto no número como no peso dos nódulos secos. As médias dos números de nódulos dos tratamentos com captã ou PCNB, aplicados antecipadamente, e do tratamento com PCNB simultâneo, foram significativamente maiores que a do controle, sem fungicida (teste de Dunnett). Para o solo não esterilizado, não se observaram diferenças significativas entre as médias do número de nódulos dos tratamentos com fungicidas em relação ao controle (Quadro 2). Não se coletaram dados de peso de nódulos secos para o solo não irradiado.

Da análise dos dados referentes à forma de aplicação dos fungicidas, observa-se que peso e número de nódulos não foram significativamente afetados em solo esterilizado. Entretanto, naquele não esterilizado, o número de nódulos 
foi favorecido pela aplicação simultânea, mas nenhum desses tratamentos se diferenciou significativamente do controle sem fungicida - Quadro 3: a menor nodulação do solo irradiado pode ter sido causada por liberação do nitrogênio, que normalmente ocorre com a irradiação do solo $\left({ }^{6}\right)$.

A literatura tem demonstrado que PCNB não prejudica a nodulação, quando as sementes são tratadas, inoculadas e plantadas imediatamente, como observaram GRAHAM et alii (1980) em feijoeiro. Também STAPHORST \& STRIJDOM (1976) verificaram ausência de influência prejudicial em peso de nódulos de $V$. unguiculata, tanto aos 25 como aos 42 dias após o plantio, em duas estirpes de Rhizobium testadas.

No entanto, efeitos prejudiciais do PCNB na nodulação foram observados por CURLEY \& BURTON (1975). GRAHAM et alii (1980), mantendo um intervalo de tempo entre inoculação de sementes testadas com fungicidas e plantio, notaram decréscimo da nodulação em certos tipos de solo.

QUADRO 1. Número e peso de nódulos secos e teor de ureídeos em folhas de amendoim amostradas em dois períodos de plantas cujas sementes foram tratadas ou não com fungicidas e inoculadas com Rhizobium sp. Plantas cultivadas em casa de vegetação, em solo irradiado com radiação gama. Médias de cinco repetiçōes

\begin{tabular}{|c|c|c|c|c|}
\hline \multirow[b]{2}{*}{ Tratamentos } & \multicolumn{2}{|c|}{ Nódulos $(\sqrt{x+1})$} & \multicolumn{2}{|c|}{ Ureídeos $(\sqrt{x+1})\left({ }^{2}\right)$} \\
\hline & Número & Peso ( $\left.{ }^{1}\right)$ & 49 dias & 73dias \\
\hline Sem inoculaçāo. . . . . . . . . & 4,1 & 4,1 & 8,0 & 4,2 \\
\hline Com inoculação . . . . . . . & 6,3 & 4,7 & 9,2 & 4,5 \\
\hline Tirã simultâneo... . . . . . . . & 7,5 & 5,5 & 10,5 & 3,8 \\
\hline Captã simultâneo $\ldots \ldots \ldots$. & 7,5 & 5,0 & 10,5 & 5,0 \\
\hline PCNB simultâneo $\ldots \ldots \ldots \ldots$ & $8,8^{*}$ & 5,9 & 10,5 & 4,3 \\
\hline Tirā antecipado. . . . . . . . . & 8,1 & 5,5 & 7,8 & 5,0 \\
\hline Captã antecipado . . . . . . & $9,0^{*}$ & 5,9 & 8,8 & 3,3 \\
\hline PCNB antecipado . . . . . . . & $8,6^{*}$ & 5,9 & 7,0 & 4,0 \\
\hline$C V(\%) \ldots \ldots \ldots \ldots \ldots$ & 16,6 & 13,3 & 18,7 & 20,8 \\
\hline
\end{tabular}

(1) Dados transformados dos originais expressos em mg/vaso (duas plantas/vaso).

(2) Dados transformados dos originais expressos em $\mu \mathrm{g} / \mathrm{gde}$ materia fresca.

(*) Diferença significativa (teste bilateral de Dunnett).

(6) SAITO, S.M.T. Comunicação pessoal. 
QUADRO 2. Número de nódulos e teor de ureídeos em folhas de amendoim amostradas em dois períodos, de plantas cujas sementes foram tratadas ou não com fungicidas e inoculadas com Rhizobium sp. Plantas cultivadas em casa de vegetaçáo, em solo não irradiado. Médias de cinco repetiçōes

\begin{tabular}{|c|c|c|c|}
\hline \multirow{2}{*}{ Tratamentos } & \multirow{2}{*}{$\begin{array}{l}\text { Número de } \\
\text { nódulos }\end{array}$} & \multicolumn{2}{|c|}{ Ureídeos $\left({ }^{1}\right)$} \\
\hline & & 49 dias & 73 dias \\
\hline & & $\sqrt{x+1}$ & 56 \\
\hline Sem inoculação . . . . . . . . . . . & 17,2 & 7,3 & 5,6 \\
\hline Com inoculação . . . . . . . . . & 17,7 & 7,9 & 5,0 \\
\hline Tirã simultâneo . . . . . . . . . . . . & 19,5 & 7,2 & 5,2 \\
\hline Captã simultâneo . . . . . . . . . & 19,1 & 7,8 & 5,5 \\
\hline PCNB simultâneo . . . . . . . . . & 16,9 & 6,4 & 4,7 \\
\hline Tïã antecipado........... & 16,6 & 6,6 & 4,5 \\
\hline Captã antecipado . . . . . . . . & 17,7 & 6,9 & 4,1 \\
\hline PCNB antecipado .......... & 16,9 & 7,2 & 4,7 \\
\hline$C V(\%) \ldots \ldots \ldots \ldots \ldots$ & 7,9 & 18,5 & 13,4 \\
\hline
\end{tabular}

(1) Dados transformados dos originais expressos em $\mu \mathrm{g} / \mathrm{gde}$ matéria fresca.

QUADRO 3. Número e peso de nódulos secos observados em amendoim, em plantas cujas sementes foram inoculadas com Rhizobium sp. e simultaneamente tratadas com fungicidas, ou previamente tratadas e depois inoculadas. Efeito conjunto de três fungicidas. Médias de quinze repetiçōes

\begin{tabular}{|c|c|c|c|}
\hline \multirow{3}{*}{$\begin{array}{l}\text { Época de aplicação } \\
\text { dos fungicidas }\end{array}$} & \multicolumn{3}{|c|}{ Nodulação } \\
\hline & \multicolumn{2}{|c|}{ Solo irradiado } & \multirow{2}{*}{$\frac{\text { Solo não irradiado }}{\text { Número }}$} \\
\hline & Número & Peso $\left({ }^{1}\right)$ & \\
\hline Simultânea & 7,9 & 5,5 & $18,5^{*}$ \\
\hline Antecipada ............. & 8,6 & 5,8 & 17,1 \\
\hline
\end{tabular}

(1) Dados transformados dos originais expressos em mg/vaso (duas plantas/vaso).

(*) Diferença significativa (teste $\mathrm{F}$ ).

STAPHORST \& STRIJDOM (1976) observaram boa nodulação com duas estirpes de Rhizobium 42 dias após o plantio de sementes de Vigna unguiculata tratadas com captã. NERY \& DÖBEREINER (1975) notaram ausência de efeito tóxico do mesmo produto na nodulação de soja, quando o inoculante foi colocado no solo, sem contato direto com o fungicida. KRATKA \& UJEVIC (1970) observaram que, em doses equivalentes a $0,3 \mathrm{~kg}_{\mathrm{g}}$ ha ${ }^{-1}$ de captã, não houve efeito 
na nodulação de ervilhaca. Efeitos altamente prejudiciais do captã foram constatados por GRAHAM et alii (1980) e STAPHORST \& STRIJDOM (1976), em avaliação da nodulação efetuada aos 25 dias após o plantio e por CURLEY \& BURTON (1975) e NERY \& DÖBEREINER (1975), quando o produto foi aplicado junto com o inoculante, reduzindo significativamente o número de nódulos e o nitrogênio fixado.

Efeitos não prejudiciais do tirã na nodulação foram constatados por STAPHORST \& STRIJDOM (1976), CURLEY \& BURTON (1975), RUSCHEL \& COSTA (1966) e GRAHAM et alii (1980).

\section{Concentração de ureídeos}

Os resultados das análises de ureídeos estão nos quadros 1, 2 e 4. Os dados do quadro 1 , referentes às plantas do solo esterilizado, revelam que houve uma influência positiva dos três fungicidas no teor de ureideos até a primeira amostragem. Em solo não esterilizado, essa diferença só foi observada na segunda amostragem, refletindo a mesma tendência dos dados de nodulação (Quadro 2). Na comparação do efeito conjunto de época de aplicação, verificou-se, contrariamente aos dados de nodulação, que o teor de ureídeos nas folhas coletadas aos 49 dias foi maior para a aplicação simultânea do que para a antecipada (Quadro 4). Os teores de ureídeos foram menores na segunda amostragem, o que possivelmente reflita menor fixação de nitrogênio no final do ciclo vegetativo ou transferência direta às vagens (TEIXEIRA et alii, 1981). Na segunda amostragem, nas plantas em solo esterilizado, houve uma tendência da aplicação antecipada em reduzir o teor de ureídeo nas folhas (Quadro 4). Tais efeitos são dificeis de interpretar, particularmente sem dados e teores de nitrogênio. É possivel que os fungicidas tenhar: influenciado o desenvolvimento fisiológico das plantas (eventualmente efeito hormonal), transporte e/ou transferência do nitrogênio para as vagens.

QUADRO 4. Médias dos teores de ureídeos observados em duas Épocas em folhas de amendoim, obtidas de plantas cujas sementes foram inoculadas com Rhizobium sp. e simultaneamente tratadas com fungicidas, ou previamente tratadas e depois inoculadas. Efeito conjunto de três fungicidas. Médias de quinze repetiçōes

\begin{tabular}{|c|c|c|c|c|}
\hline \multirow{2}{*}{$\begin{array}{l}\text { Época de aplicação } \\
\text { dos fungicidas }\end{array}$} & \multicolumn{2}{|c|}{ Solo irradiado $\left({ }^{1}\right)$} & \multicolumn{2}{|c|}{ Solo não irradiado $\left({ }^{1}\right)$} \\
\hline & 49 dias & 73 dias & 49 dias & 73 dias \\
\hline & 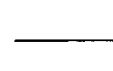 & $-(\sqrt{ }$ & F1) & - \\
\hline Simultânea $\ldots \ldots \ldots \ldots \ldots$ & $10,5^{*}$ & 4,4 & 7,2 & $5,1^{*}$ \\
\hline Antecipada $\ldots \ldots \ldots \ldots \ldots$ & 8,7 & 4,1 & 6,9 & 4,4 \\
\hline
\end{tabular}

(1) Dados transformados dos originais expressos em $\mu \mathrm{g} / \mathrm{g}$ materia fresca.

(*) Diferença significativa (teste F). 


\section{SUMMARY}

\section{COMPATIBILITY BETWEEN PEANUT SEED PRESERVATION WITH FUNGICIDES, SURVIVAL OF RHIZOBIA AND NODULATION}

$A r_{s}$ experiment was carried out to test the compatibility between peanut seed treated with the fungicides captan, PCNB and thiram with rhizobia inoculation. The application of the fungicides was done either simultaneously or ten days before the inoculation of the seeds. A control, without inoculation, was included. Countings of rhizobia on the seed were made immediately after inoculation and four hours after, by dilution and drop plating technique. In order to study the effect of treatments on nodulation and nitrogen fixation, treated and untreated seeds were planted in gamma irradiated soil and nodulation and leaf ureid content were later evaluated. It was observed that only captan applied to the seed simultaneously with inoculation was significantly deleterious to survival of the rhizobia. In general the application of the fungicide ten days before inoculation caused no significant harmfull effect to survival of rhizobia on the seed.

Index terms: Rhizobium-fungicide compatibility, peanut, Arachis hypogaea L.

\section{AGRADECIMENTOS}

Os autores agradecem à IBRAS-CBO Indústrias Cirúrgicas e Ópticas S.A., a esterilização das sementes e do solo, à Coordenadoria de Assistência Técnica Integral (CATI), a análise química dos fungicidas e à Seção de Fitoquímica - IAC o auxílio na análise de ureídeos.

\section{REFERÊNCIAS BIBLIOGRÁFICAS}

AFIFI, N.M.; MOHARRAM, A.A.; HAMDI, V.A. \& ABDEL-MALEK, Y. Sensitivity of Rhizobium species to certain fungicides. Archiv fuer Mikrobiologie, 66:121-128, 1969.

BRACKEL, J. Action sur le Rhizobium de divers fongicides et insecticides commerciaux. Annales del' Institut Pasteur, 105:143-149, 1963.

CURLEY, R.L. \& BURTON, J.C. Compatibility of Rhizobium japonicum with chemical seed protectants. Agronomy Journal, 67:807-808, 1975.

DIATLOFF, A. The effects of some pesticides on root nodule bacteria and subsequent nodulation. Australian Journal Experimental Agriculture and Animal Husbandry, 10:562-567, 1970 ,

FISCHER, D.J. Effects of some fungicides on Rhizobium trifolii and its symbiotic relationship with white clover. Pesticide Science, 7:10-18, 1976.

GIARDINI, A.R.; HESPANHOL, R.E. \& LOPES, E.S. Seleçăo de mutantes resistentes à estreptomicina e espectiomicina de estirpes de Rhizobium spp. efetivas em amendoim. Relatório Anual da Seção de Microbiologia do Solo do Instituto Agronômico, Campinas, 1980. 
GILLBERG, B.O. On the effects of some pesticides on $R$ hizobium and isolation of pesticide-resistant mutants. Archiv fuer Mikrobiologie, 75:203-208, 1971.

GRAHAM, P.H.; OCAMPO, G.; RUIZ, L.D. \& DUQUE, A. Survival of Rhizobium phaseoli in contact with chemical seed protectants. Agronomy Journal, 72:625-627, 1980.

KECSKÉS, M. Comparative investigations of the action of fungicides on Rhizobium leguminosarum Frank and its symbiosis with Vicia sativa L. Mededelingen van de Facultfit Landbouw wetenschappen Rijksuniversitfit Gent, 35:505-514, 1970.

\& VINCENT, J.M. The effect of some fungicides on Rhizobium leguminosarum species. 1 - Laboratory investigations. Agrokèmia Ės Talajtan, 18:57-70, 1969.

KRATKA, J. \& UJEVIC, I. Seed treatment of winter vetch with fungicides and their effect on formation of root nodules. Pol'nohospodarstvo, 16:203-213, 1970.

LAGO, A.A.; ORTOLANI, D.B.; ZINK, E. \& FERNANDES, C.O. Efeito de diversos tratamentos fungicidas na longevidade de sementes de amendoim. Semente, Brasilia, 1:26-34, 1976.

MAKAWI, A.A.M. \& ABDEL-GHAFFAR, A.S. The effect of some pesticides on the grow th of root-nodule bacteria. Journal of Microbiology of the United Arab Republic, 5:109-117, 1970.

NERY, M. \& DÖBEREINER, J. Efeito de fungicidas pré-emergentes, na nodulação e fixação de nitrogênio em soja. In: CONGRESSO BRASILEIRO DE CIÊNCIA DO SOLO, 15., Campinas, 1975. Anais. p.177-180.

ODEYEMI, O. \& ALEXANDER, M. Resistence of Rhizobium strains to phygon, spergon, and thiram. Applied and Environmental Microbiology, 33:784-790, 1977.

RAIJ, B. van \& QUAGGIO, J.A. Métodos de análise de solo para fins de fertilidade. Campinas, Instituto Agronômico, 1983. 31p. (Boletim técnico, 81)

RUSCHEL, A.P. \& COSTA, W.F. Fixaçāo simbiótica de nitrogênio atmosférico em feijão (Phaseolus vulgaris L.). III - Influência de alguns inseticidas e fungicidas. Pesquisa Agropecuária Brasileira, Brasília, 1:147-149, 1966.

SALEMA, M.P.; PARKER, C.A. \& KIDBY, D.K. The survival of Rhizobium cells on seed. In: AUSTRALIAN LEGUME NODULATION CONFERENCE, 6., 1979. Proceedings. Perth, Univ. Western Australia. p.50-53.

STAPHORST, J.L. \& STRIJDOM, B.W. Effects on Rhizobium on fungicides applied to legume seed. Phytophylactica, 8:47-54, 1976.

STREETER, J.G. Allantoin and allantoic acid in tissues and stem exudate from field grown soybean plants. Plant Physiology, 63:478-480, 1979.

TEIXEIRA, J.P.F.; SILVA, M.T.R.; LOPES, E.S. \& GIARDINI, A.R. Ocorrência de ureídeos em folhas de amendoim (Arachis hipogaea L.) como indicativo de fixação simbiótica de nitrogênio atmosférico. Bragantia, Campinas, 40:193-197, 1981.

VINCENT, J.M. A manual for the practical study of the root-nodule bacteria. Oxford, Black well Scientific Publication, 1970. 150p. (IBP. HANDBOOK, 15)

YOUNG, E.G. \& CONWAY, C.F. On estimation of allantoin by the Rimini-Schryver reaction. Journal of Biological Chemistry, 142:839-853, 1942. 